Open Access

\title{
Cardiopulmonary bypass in the newborn: effects of circulatory cell-free hemoglobin and hyperoxia evaluated in a novel rat pup model
}

Åsa Jungner ${ }^{1,2,4^{*}}$ D, Suvi Vallius ${ }^{1}$, Matteo Bruschettini ${ }^{1,2}$, Olga Romantsik ${ }^{1,2}$, Magnus Gram ${ }^{1,3}$ and David Ley ${ }^{1,2}$

\section{* Correspondence:}

asa.jungner@med.lu.se

${ }^{1}$ Department of Clinical Sciences Lund, Pediatrics, Skane University Hospital, Lund University, Lund, Sweden

${ }^{2}$ Department of Clinical Sciences Lund, Pediatric Surgery and Neonatal Care, Skane University Hospital, Lund University, Lund, Sweden

Full list of author information is available at the end of the article

\begin{abstract}
Background: Infants with congenital heart defects (CHD) are at risk for white matter brain injury. This novel rat pup model characterizes the systemic effects of intravasal cell-free hemoglobin and hyperoxia, hypothesizing that immature endogenous scavenging systems relate to increased vulnerability to conditions present during cardiopulmonary bypass (CPB).
\end{abstract}

Methods: Plasma pharmacokinetics of cell-free human hemoglobin $(\mathrm{Hb})$ was determined after intraperitoneal (i.p.) administration in postnatal day 6 (P6) rat pups. Cell-free hemoglobin degradation, scavenger- and oxidative stress responses in altered oxygen environments were evaluated in $\mathrm{P} 6$ rat pups exposed to i.p. cell-free $\mathrm{Hb}$ or vehicle and subjected to hyperoxia or normoxia for $24 \mathrm{~h}$. Plasma and liver were analyzed for free heme, haptoglobin, hemopexin, heme-oxygenase 1, and 8-OHdG at 3-120 h post-injection. Baseline scavenging properties were evaluated in P0-P12 rat pups.

Results: Cell-free Hb displayed peak plasma concentrations of $3.6 \pm 0.5 \mathrm{mg} / \mathrm{mL}$ (mean \pm $\mathrm{SD}$ ) at $3 \mathrm{~h}$ post-administration. Animals exposed to cell-free $\mathrm{Hb}$ demonstrated a 30 -fold increase in plasma haptoglobin and a decrease in plasma hemopexin to $1 / 6$ of concentrations observed in pups exposed to vehicle. Exposure to cell-free $\mathrm{Hb}$ and hyperoxia mediated increased plasma concentrations of free heme (72.7 $\pm 19.5 \mu \mathrm{M}$, mean $\pm \mathrm{SD}$ ) compared to exposure to cell-free $\mathrm{Hb}$ and normoxia $(49.3 \pm 13.1 \mu \mathrm{M})$ at $3 \mathrm{~h}$, and an elevated hepatic mRNA expression of heme-oxygenase 1. mRNA expression of haptoglobin and hemopexin was increased in animals exposed to hemoglobin with a mitigated response in pups exposed to hemoglobin and hyperoxia. Animals exposed to hyperoxia displayed an increase in hepatic transcription of scavenger proteins at $24 \mathrm{~h}$. Combined exposure to cell-free $\mathrm{Hb}$ and hyperoxia mediated an increased DNAoxidation at $6 \mathrm{~h}$, whereas all insults conveyed a decrease in DNA-oxidation at $120 \mathrm{~h}$.

Conclusions: In this study, we present a novel rat pup model with scavenging characteristics and brain maturation similar to newborns with CHD. We have confirmed a distinct scavenger response after exposure to systemic cell-free hemoglobin. We have indications of an accelerated metabolism of cell-free $\mathrm{Hb}$ and of an altered transcription of scavenger proteins in a hyperoxic environment. We believe that this model will prove valuable in future delineation of inflammatory and oxidative end-organ damage following CPB.

(Continued on next page) 
(Continued from previous page)

Keywords: Congenital heart disease, Cardiopulmonary bypass, Cell-free

hemoglobin, Hyperoxia, Neonate, Animal model, Inflammation, Oxidative stress,

Haptoglobin, Hemopexin

\section{Background}

The management of congenital heart defects (CHD) has seen remarkable improvements in mortality rates over the last decades. With increasing survival, it has been apparent that newborn infants with CHD requiring early correction on cardiopulmonary bypass $(\mathrm{CPB})$ are at an increased risk for impaired long-term neurodevelopmental outcome with diffuse white matter brain injury as the predominant neuro-radiological correlate [1]. In a recent scientific statement by the American Heart Association, survival rate was recognized as above $80 \%$ in newborns with $\mathrm{CHD}$ requiring surgery on $\mathrm{CPB}$, whereas $30-50 \%$ of long-time survivors exhibit varying degrees of impaired neurodevelopmental outcome [2].

CPB-assisted open-heart surgery results in a powerful systemic inflammatory response and oxidative stress [3-5]. Initiating events are likely to be multifactorial with ischemia-reperfusion and contact with non-endothelial surfaces as often-cited initiators [6]. Circulation of blood in the CPB circuit is known to result in mechanically induced hemolysis with increased levels of cell-free (extracellular) hemoglobin $(\mathrm{Hb})$, which have been suggested as causally involved in organ dysfunction and physiological disturbances following CPB [7-9].

Cell-free $\mathrm{Hb}$ is a highly reactive molecule that is rapidly oxidized from ferrous $\left(\mathrm{Fe}^{2+}\right.$, denoted oxyHb) to ferric $\left(\mathrm{Fe}^{3+}\right.$, denoted metHb) $\mathrm{Hb}$ while producing reactive oxygen species and reducing the bioavailability of NO [10, 11]. Ferric Hb readily releases free heme, a redox reactive molecule with a capacity of inflicting oxidative damage to lipids, proteins, and DNA, and also of toxic cytolytic effects by intercalation into cell membranes [12, 13]. Moreover, free heme has been suggested as a TLR4-ligand, indicating an inflammation-inducing propensity [14]. The impact of cell-free $\mathrm{Hb}$ on the inflammatory process and oxidative stress following $\mathrm{CPB}$ is not well characterized; neither are the temporal aspects of cell-free $\mathrm{Hb}$ metabolism in a hyperoxic environment.

The major human endogenous scavenger systems of cell-free $\mathrm{Hb}$ and its metabolite heme are haptoglobin ( $\mathrm{Hp}$ ) and hemopexin ( $\mathrm{Hpx}$ ) [15-17]. These have been well characterized as abundant and efficient in the human adult and in mature animal models. The newborn infant has, in comparison, low endogenous levels of these plasma proteins $[18,19]$, suggesting a heightened vulnerability to the potentially toxic effects of cell-free $\mathrm{Hb}$ and its down-stream metabolites.

Oxygen is a toxic molecule when in surplus. Previous research from our and other groups show that hyperoxemia per se or during reperfusion following hypoxia-ischemia plays a causal role in end-organ damage [20,21]. Clinical studies performed during pediatric $\mathrm{CPB}$ suggest that levels of oxidation, inflammation, and end-organ damage markers are dependent on whether supra-normal or normal levels of oxygen are used when on CPB in both cyanotic and non-cyanotic patients [22, 23]. Cyanotic patients 
appear to fare worse in terms of oxidative damage than non-cyanotic patients on $\mathrm{CPB}$ even when normoxia is applied [24].

The combined effects of circulating cell-free $\mathrm{Hb}$ and hyperoxemia have, to the best of our knowledge, not previously been studied in either immature or mature in vivo model systems. Both insults are of clinical relevance during CPB in the newborn period and occur simultaneously. We hypothesized that the additive effects of cell-free $\mathrm{Hb}$ and hyperoxemia would result in a potentiated induction of harmful mechanisms related to cell-free hemoglobin toxicity and thereby lead to aggravated tissue damage. To this end, we developed a novel immature rat pup model aiming to characterize the systemic effects of intravasal cell-free $\mathrm{Hb}$ and hyperoxemia. Postnatal day 6 (P6) rat pups were exposed to a combined insult of (1) systemic cell-free $\mathrm{Hb}$ or vehicle solution administered intraperitoneally (i.p.) and/or (2) a hyperoxic or normoxic environment and examined for endogenous scavenger and oxidative stress responses. Here, we present data displaying our novel rat pup model as a valuable tool for investigation of systemic hemolysis and concomitant hyperoxemia in an immature physiology with a potential value for future studies on end-organ damage.

\section{Methods}

Animals

The experiments were performed on a total of 319 Wistar rat pups (Scanbur Research A/S Karslunde, Denmark) from 45 litters. All rat pups were nursed and fed by lactating dams throughout the study. Animals were handled according to Swedish animal welfare legislation. The research protocol was approved by the Swedish Animal Ethics Committee in Lund, permit nr M48-14.

\section{Preparation of human cell-free $\mathrm{Hb}$}

Human cell-free $\mathrm{Hb}$ was purified as previously described [25] from human adult red blood cells obtained from the blood center in Lund (Sweden). The Hb concentration was quantified using Plasma/Low Hb (Hemocue, Ängelholm, Sweden). The Hb was dissolved in Ringer's Acetate (Baxter, Deerfield, Ill, USA) and purified from endotoxin contamination using EndoTrap as described by the manufacturer (Hyglos GmbH, Germany). The absolute purity of $\mathrm{Hb}$ from contamination with endotoxin was determined by QCL-1000 ${ }^{\text {mix }}$ Endpoint Chromogenic LAL Assay as described by the manufacturer (Lonza, Switzerland).

\section{Experimental setup 1: pharmacokinetics of cell-free human $\mathrm{Hb}$ following i.p. administration}

Litter-mixed P6 Wistar rat pups were sedated with isoflurane in room air and injected i.p. with a weight-based dose of endotoxin-free cell-free human $\mathrm{Hb}$ purified as described above or with corresponding volume of vehicle (Ringer's Acetate). Dose calculations were made assuming (1) a plasma volume of $40 \mathrm{ml} / \mathrm{kg}$, (2) an estimated peritoneal transfer of $1 / 10$ of administered dose [26], and (3) an attempted plasma concentration of $5 \mathrm{mg} / \mathrm{ml}$, resulting in administered doses of $2 \mathrm{~g} / \mathrm{kg}$ of cell-free hemoglobin from a solution containing $200 \mathrm{mg} / \mathrm{mL}$. Animals $(n=5-7$ at respective time point) were sacrificed by decapitation at $0.5,1,2,3,4,5,6,8,12,18$, and $24 \mathrm{~h}$ following i.p. injection. The study design is illustrated in Fig. 1a. Blood samples were 


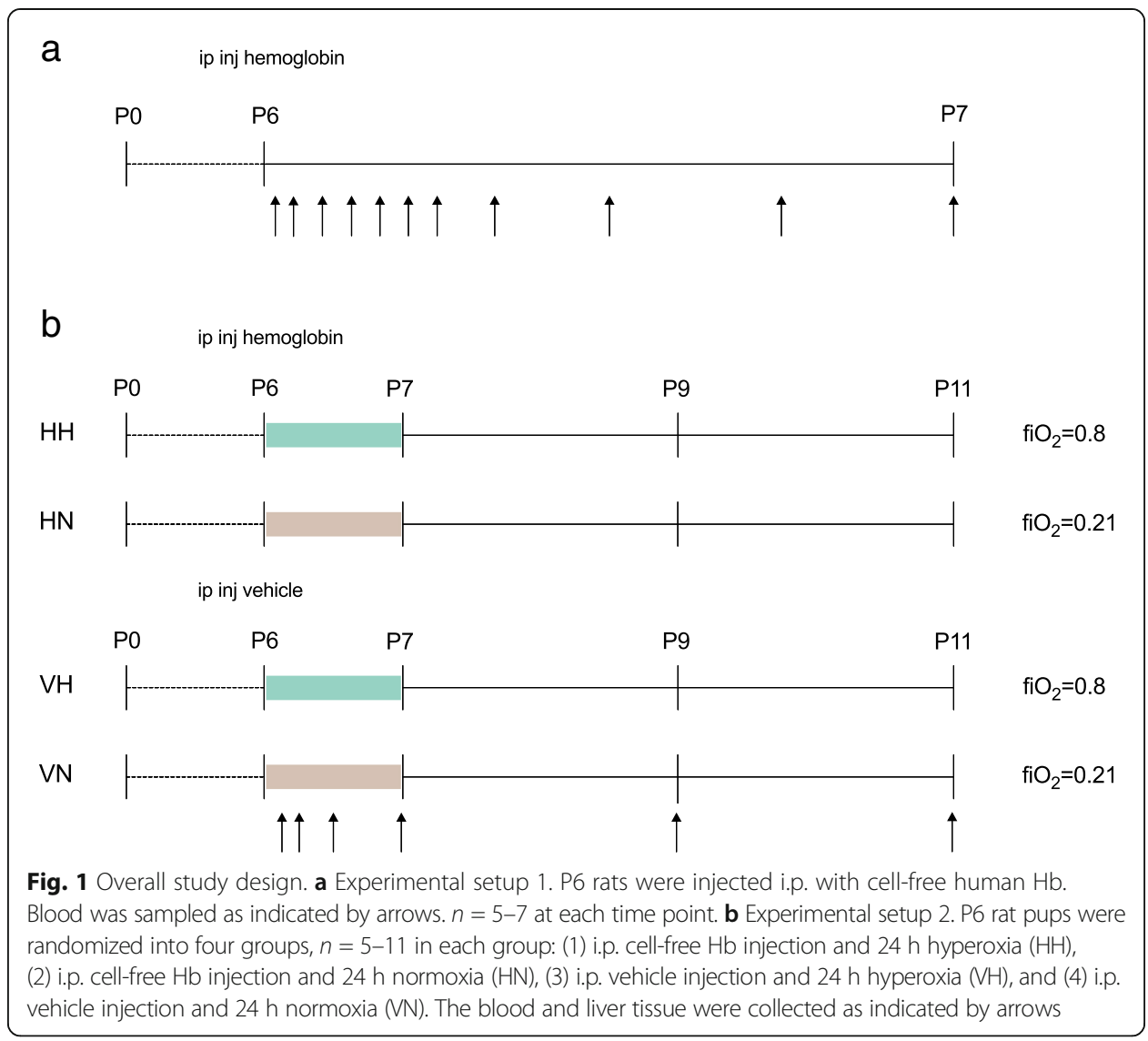

collected in sodium-citrate tubes (MiniCollect 450413, Greiner Bio-One, Kremsmünster, Austria); plasma was separated by centrifugation at $2000 \times \mathrm{g}$ for $10 \mathrm{~min}$ and stored at $80{ }^{\circ} \mathrm{C}$ until further use.

\section{Experimental setup 2: systemic exposure to cell-free human $\mathrm{Hb}$ and hyperoxemia}

Litter-mixed P6 Wistar rat pups were randomized into one of the following groups: (1) rat pups receiving i.p. cell-free $\mathrm{Hb}$ injections and exposure to hyperoxia (group denoted $\mathrm{HH}$ ), (2) rat pups receiving i.p. cell-free $\mathrm{Hb}$ injections and exposure to normoxia (group denoted $\mathrm{HN}$ ), (3) rat pups receiving i.p. vehicle injections and exposure to hyperoxia (group denoted $\mathrm{VH}$ ), and (4) rat pups receiving i.p. vehicle injections and exposure to normoxia (group denoted $\mathrm{VN}$ ). Overall study design including the respective study groups is illustrated in Fig. 1b.

The experimental procedure was carried out as follows: rat pups were sedated with isoflurane in room air and injected i.p. with a weight-based dose of endotoxin-free cellfree human $\mathrm{Hb}$ purified as described above or with corresponding volume of vehicle (Ringer's Acetate). Dose calculations of cell-free $\mathrm{Hb}$ were made as described above. After recovery, pups were returned to a lactating dam and placed in neonatal incubator (Dräger 8000, Drägerwerk AG, Lübeck, Germany) with exposure to either a hyperoxic (fiO2 0.8 ) or a normoxic (fiO2 0.21 ) condition for $24 \mathrm{~h}$. Oxygen concentrations within the incubators were monitored by the in-built monitoring system of the incubator and crosschecked using a portable oxygen monitor (MX300-I, Teledyne Analytical 
Instruments, Los Angeles, CA, USA). Hyperoxemia was confirmed by blood gas analysis of blood samples obtained by decapitation after $45 \mathrm{~min}$ exposure to hyperoxia. Temperature in incubators was kept constant at $28{ }^{\circ} \mathrm{C}$. After the $24 \mathrm{~h}$ exposure to hyperoxia or normoxia, animals were housed in room air and room temperature until termination.

Animals were sacrificed by decapitation at 3, 6, 12, 24, 72, and 120 h post cell-free $\mathrm{Hb}$ or vehicle administration. Blood samples were collected in sodium-citrate tubes (Greiner Bio-One); plasma was separated by centrifugation at $2000 \times g$ for $10 \mathrm{~min}$ and stored at $-80{ }^{\circ} \mathrm{C}$ until further use. Liver tissue was snap-frozen on dry ice immediately after excision and stored at $-80^{\circ} \mathrm{C}$ until further use.

\section{Analysis of cell-free $\mathrm{Hb}$}

Plasma concentration of cell-free $\mathrm{Hb}$ was evaluated using Plasma/Low Hb (Hemocue, Ängelholm, Sweden) and human Hb ELISA according to instructions from the manufacturer (Genway Biotech Inc., San Diego, Ca, USA). Ability to discriminate between cell-free rat $\mathrm{Hb}$ and cell-free human $\mathrm{Hb}$ was confirmed by analysis of plasma from animals not subjected to i.p. injection of human cell-free $\mathrm{Hb}$.

\section{Analysis of in vivo Hb-degradation}

Evaluation of in vivo $\mathrm{Hb}$-degradation was performed by analyzing the presence of free heme using the Heme Colorimetric Assay Kit (BioVision, Milpitas, CA, USA) in plasma of animals subjected to varied oxygen environments.

\section{Analysis of $\mathrm{Hb}$-scavengers in plasma}

Plasma levels of the endogenous Hb-scavengers $\mathrm{Hp}$ and Hpx were determined using rat Hp and Hpx ELISA assays as described by the manufacturer (Genway Biotech Inc.). Baseline plasma levels of $\mathrm{Hp}$ and $\mathrm{Hpx}$ were determined in rat pups not subjected to any intervention before decapitation at P0, P2, P4, P5, P6, P7, P8, and P12.

\section{RNA isolation and real-time PCR}

Expressions of Hp, Hpx, and heme oxygenase 1 (HMOX1) mRNA respectively were analyzed in liver tissue of animals terminated at 3, 12, and $24 \mathrm{~h}$. Total RNA was isolated from liver tissue using NucleoSpin ${ }^{\bullet}$ RNA/protein (Marchery-Nagel, Duren, Germany) and RNeasy Mini Kit supplied by Qiagen (Germantown, MD, USA). The OD ratio (optical density at $260 \mathrm{~nm} / 280 \mathrm{~nm}$ ) of RNA was always higher than 1.95. Reverse transcription was performed according to the manufacturer on $1.0 \mu \mathrm{g}$ total RNA using $\mathrm{RT}^{2}$ First Strand Kit (Qiagen). RT ${ }^{2}$ qPCR Primer Assays (from Qiagen) were used to quantify the mRNA expression of $\mathrm{Hp}, \mathrm{Hpx}$, and HMOX1. Data were normalized to Ribosomal protein, large, P1 (Rplp1; Qiagen). The fold change values were calculated by normalizing against the mean of the $\mathrm{VN}$ group at all time points.

\section{DNA-oxidation}

Oxidative DNA damage in plasma samples was evaluated using the OxiSelect ${ }^{\mathrm{Tu}}$ Oxidative DNA damage ELISA Kit as described by the manufacturer (Cell Biolabs Inc., San Diego, CA, USA) at 3, 6, 12, 24, and $120 \mathrm{~h}$. 


\section{Statistics}

All statistics were performed using GraphPad Prism7 software (La Jolla, CA, USA). Results are presented as mean \pm standard deviation unless otherwise stated. Comparisons between groups were made assuming parametric data using Student's $t$ test for pairwise comparisons or one-way ANOVA with post hoc Tukey's test for multiple group comparisons at respective time point. $p$ values $<0.05$ were considered significant.

\section{Results}

\section{Pharmacokinetics of cell-free human $\mathrm{Hb}$}

The pharmacokinetics of cell-free human $\mathrm{Hb}$ was analyzed in plasma at 0-24 $\mathrm{h}$ following i.p. administration. A rapid circulatory uptake of cell-free human $\mathrm{Hb}$ was observed, reaching a maximum level of $3.6 \pm 0.5$ (mean $\pm \mathrm{SD}$ ) $\mathrm{mg} / \mathrm{ml}$ at $3 \mathrm{~h}$ after injection followed by an elimination with no circulatory levels of cell-free human $\mathrm{Hb}$ detected at $24 \mathrm{~h}$ post-injection (Fig. 2).

\section{Hb-degradation in vivo}

$\mathrm{Hb}$ degradation in vivo was evaluated by analyzing the levels of the $\mathrm{Hb}$-metabolite free heme in plasma at 3-24 h post i.p. administration of cell-free human $\mathrm{Hb}$. Free heme was only detectable in plasma of animals exposed to cell-free $\mathrm{Hb}(\mathrm{HH}+\mathrm{HN})$. Maximal concentrations were reached at $3 \mathrm{~h}$ post i.p. administration and declined thereafter with no detectable plasma concentrations at $24 \mathrm{~h}$ (Fig. 3a). Animals exposed to the combined insult $(\mathrm{HH})$ had a significantly higher concentration of plasma heme at $3 \mathrm{~h}$ $(72.7 \pm 19.5 \mu \mathrm{M}$ (mean $\pm \mathrm{SD})$ ) as compared to those exposed to $\mathrm{Hb}$ and normoxia (HN; $49.3 \pm 13.1 \mu \mathrm{M}$ (mean $\pm \mathrm{SD}), p=0.02$ ).

The hepatic mRNA expression of the heme-degrading protein HMOX1 was analyzed at 3-24 h post i.p. injection and was found to be significantly increased at $3 \mathrm{~h}$ in the $\mathrm{HH}$ group as compared to the $\mathrm{HN}$ group $(p<0.0001)$ and the $\mathrm{VN}$ group $(p<0.0001)$ (Fig 3b). At $12 \mathrm{~h}$, the $\mathrm{HH}$ group had a sustained elevated expression of HMOX1 compared to the VN group $(p=0.04)$. A significantly increased HMOX1 mRNA expression

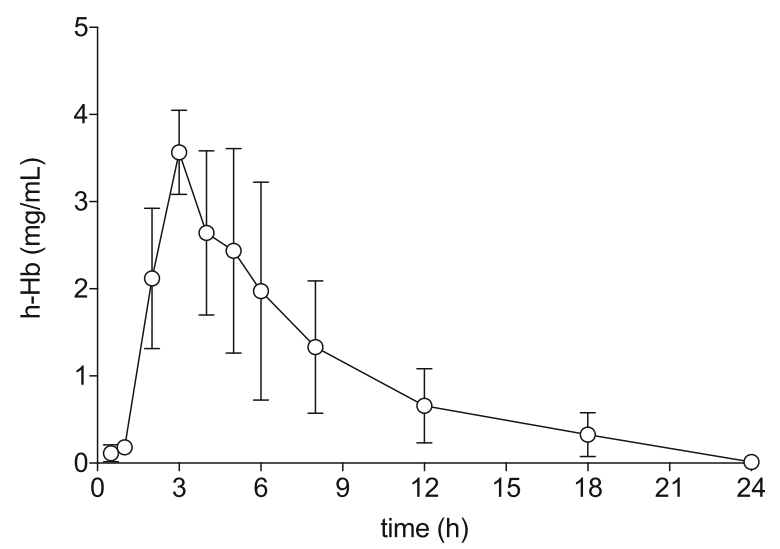

Fig. 2 Human cell-free Hb pharmacokinetics (mean \pm SD) following i.p. administration. $n=5-7$ at each time point 


\section{a}

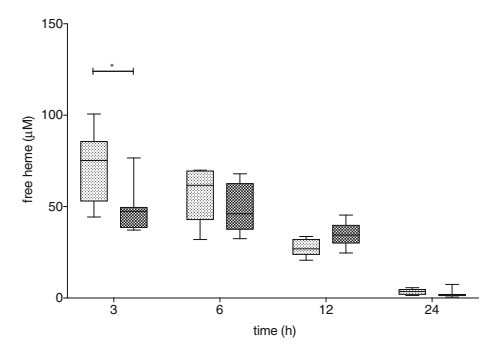

b

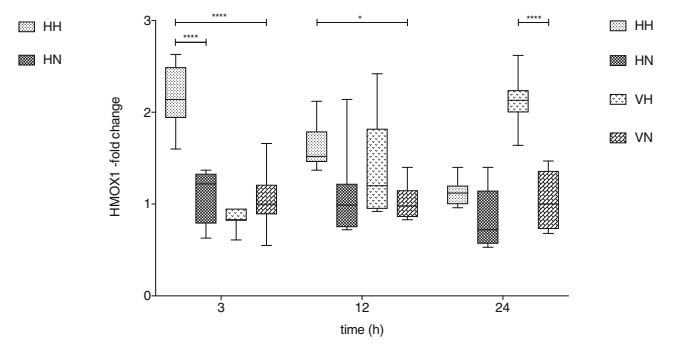

Fig. $3 \mathrm{Hb}$-metabolism in vivo. a Plasma concentrations of free heme 3-24 h post i.p. administration of cell-free human Hb. $n=5-11$ in all groups. b Liver mRNA expression of HMOX 1 at 3-24 h post i.p. cell-free $\mathrm{Hb}$ injection. Fold change was calculated against VN-mean at each time point. $n=5-7$ in all groups. Results are presented as box-and-whisker plots with min and max values marked

was found in the group exposed to hyperoxia $(\mathrm{VH})$ at $24 \mathrm{~h}$ post i.p. injection as compared to the VN group $(p<0.0001)$ (Fig. 3b).

\section{Endogenous $\mathrm{Hb}$-scavenging systems}

In order to establish an understanding of the endogenous circulatory $\mathrm{Hb}$ - and hemescavenging systems, baseline levels of $\mathrm{Hp}$ (cell-free $\mathrm{Hb}$ scavenger) and Hpx (heme scavenger) were analyzed in rat pups with a postnatal age of P0-P12. The mean plasma concentrations of $\mathrm{Hp}$ were low at all postnatal ages with a nadir at P6 and a subsequent slow rise with increasing postnatal age (Fig. 4a). Hp concentrations at P0 were highly scattered and displayed fivefold maximum levels compared to concentrations in P2 rats. Hpx displayed the lowest baseline mean plasma concentration at P0 and a linear increase with increasing postnatal age (Fig. 4b).

Following i.p. administration of cell-free human $\mathrm{Hb}$ (HH and HN groups), plasma concentrations of $\mathrm{Hp}$ increased rapidly reaching a 30-fold increase as compared to baseline levels at $12 \mathrm{~h}$ (Fig. 5a). Following the peak levels at $12 \mathrm{~h}$, a decline towards baseline was observed at $24 \mathrm{~h}$ post i.p. injection. Plasma levels of $\mathrm{Hp}$ in groups not exposed to cell-free human $\mathrm{Hb}(\mathrm{VH}$ and $\mathrm{VN})$ corresponded to baseline levels at all time points.

Following i.p. cell-free human $\mathrm{Hb}$ injection ( $\mathrm{HH}$ and $\mathrm{HN}$ groups), plasma concentrations of Hpx were decreased to $1 / 6$ of levels observed in animals injected with vehicle (VN and VH groups) at $6 \mathrm{~h}$ post i.p. injection. Plasma levels of Hpx in groups not exposed to cell-free human $\mathrm{Hb}(\mathrm{VH}$ and $\mathrm{VN})$ corresponded to baseline levels at all time points (Fig. 5c).

Of note, exposure to pure hyperoxia $(\mathrm{VH})$ caused no discernible change in plasmaconcentrations of either $\mathrm{Hp}$ or $\mathrm{Hpx}$ at any time point. Hp and Hpx concentrations in plasma did not differ in the group exposed to the combined insult $(\mathrm{HH})$ as compared to those exposed to cell-free $\mathrm{Hb}$ only $(\mathrm{HN})$.

The hepatic mRNA expression of $\mathrm{Hp}$ and Hpx was evaluated at 3-24 h post i.p. cell-free human $\mathrm{Hb}$ administration. $\mathrm{Hp}$ expression was increased at $3 \mathrm{~h}(p=0.006)$, $12 \mathrm{~h}(p=0.0001)$, and $24 \mathrm{~h}(p<0.0001)$ in the group subjected to cell-free human $\mathrm{Hb}$ and normoxia $(\mathrm{HN})$ compared to the vehicle normoxia (VN) group (Fig. 5b). The group subjected to cell-free human $\mathrm{Hb}$ and hyperoxia $(\mathrm{HH})$ had an increased 

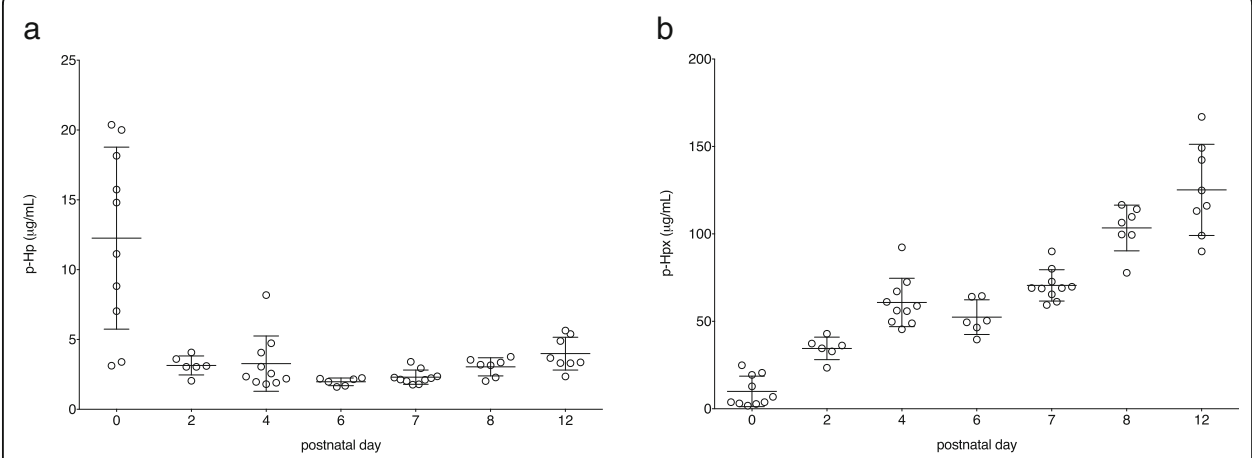

Fig. 4 Baseline $\mathrm{Hb}$ - and heme-scavenging systems. $\mathrm{Hp}(\mathbf{a})$ and $\mathrm{Hpx}$ (b) (mean $\pm \mathrm{SD}$ ) were analyzed from P0-P12. $n=6-10$ at all time points

expression of Hp mRNA at 12 and $24 \mathrm{~h}$ compared to the VN group, but the increase did not reach statistical significance.

Hpx mRNA expression was significantly increased at $3 \mathrm{~h}(p=0.003), 12 \mathrm{~h}(p<0.0001)$, and $24 \mathrm{~h}(p=0.005)$ in the group subjected to cell-free $\mathrm{Hb}$ and normoxia $(\mathrm{HN})$ compared to the VN group (Fig. 5d). The group subjected to cell-free $\mathrm{Hb}$ and hyperoxia (HH) had an increased expression of Hpx mRNA at 12 and $24 \mathrm{~h}$ compared to the VN group, but the increase did not reach statistical significance.

Notably, mRNA expression of $\mathrm{Hp}$ increased significantly in the group subjected to hyperoxia only $(\mathrm{VH})$ as compared to the $\mathrm{VN}$ group at $24 \mathrm{~h}(p=0.008)$. An increased expression of Hpx mRNA was seen in the VH group compared to the VN group at $24 \mathrm{~h}$, but the increase did not reach statistical significance (Fig. 5b, d).
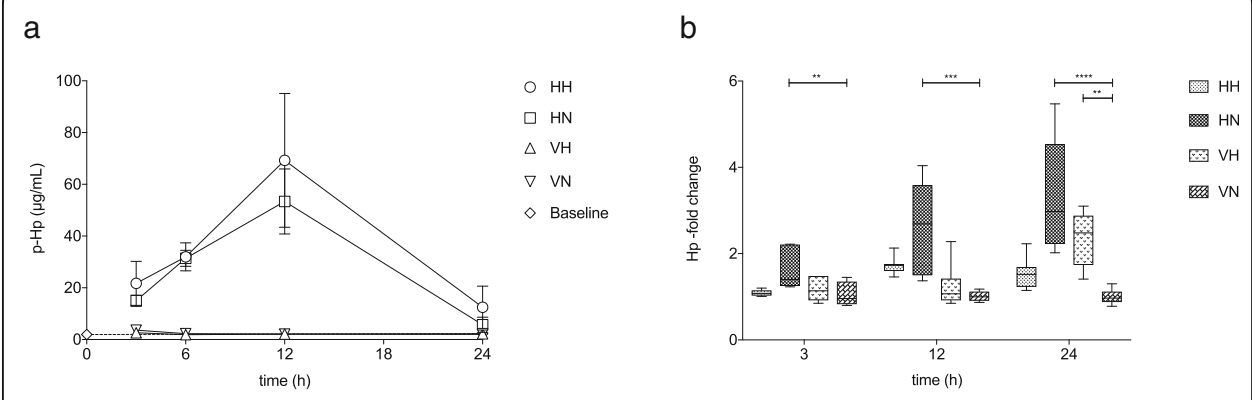

C

d
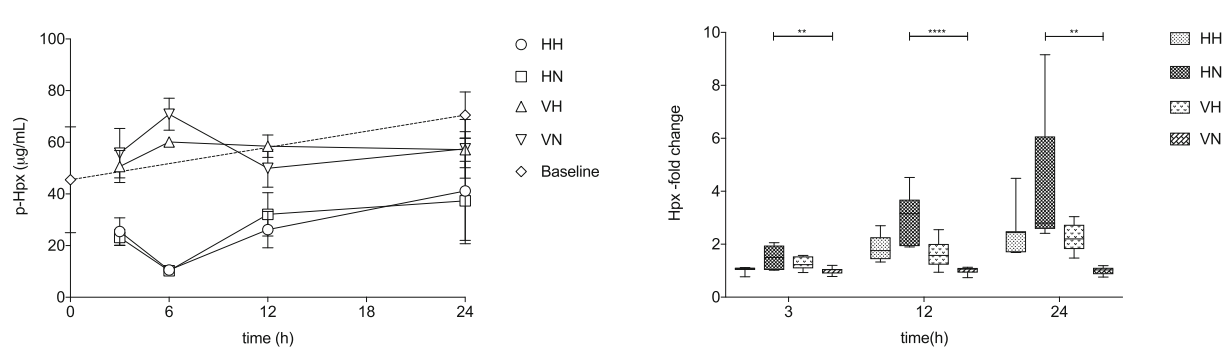

Fig. $5 \mathrm{Hb}$ - and heme-scavenging systems following exposure to cell-free human $\mathrm{Hb}$ and/or hyperoxia. Plasma concentrations $(\mathbf{a}, \mathbf{c})$ and mRNA expression in liver $(\mathbf{b}, \mathbf{d})$ of $\mathrm{Hp}(\mathbf{a}, \mathbf{b})$ and $\mathrm{Hpx}(\mathbf{c}, \mathbf{d})$ at 3-24 h following i.p. injection. Fold change mRNA expression was calculated against VN-mean at each time point. $n=5-18$ in all groups. Results are presented as mean \pm SD for $\mathbf{a}$ and $\mathbf{c}$ and as box-and-whisker plots with min and max values marked for $\mathbf{b}$ and $\mathbf{d}$ 


\section{Systemic oxidative stress}

The level of systemic oxidative stress measured as DNA-oxidation (8-OHdG) was evaluated in plasma at 3-120 h post i.p. injection. Animals exposed to the combined insult of cell-free human $\mathrm{Hb}$ and hyperoxia $(\mathrm{HH})$ showed a significant increase in plasma DNAoxidation as compared to animals injected with vehicle and subjected to normoxia (VN) at $6 \mathrm{~h}(p=0.02)$. At $120 \mathrm{~h}$, all groups subjected to any insult $(\mathrm{HH}, \mathrm{HN}$, and $\mathrm{VH})$ displayed significantly lower values of DNA-oxidation as compared to the VN group (Fig. 6).

The dataset supporting our results can be found as an Additional file 1.

\section{Discussion}

Hyperoxemia and elevated levels of systemic cell-free $\mathrm{Hb}$ are insults with an increased potential for toxicity in an immature system compared to an adult counterpart. Both term and preterm neonates have a proven susceptibility to oxygen toxicity [27] and their endogenous Hb-scavenger resources are scarce [18, 19]. The interplay between systemic inflammation and hyperoxic damage is complex and possibly dependent on the temporal relation of events [28-30]. In this study, we present a rat pup model with a progressive increase in circulatory cell-free $\mathrm{Hb}$ and simultaneous hyperoxemia that accurately mimics the temporal relationship between induced hemolysis and exposure to hyperoxia during $\mathrm{CPB}$.

Rat pups have been used extensively for exploring mechanisms of neonatal brain damage. Brain maturity in a P7 rat pup is considered similar to that of a newborn infant born at term [31]. Although infants with congenital cardiac defects are mainly born at term, their brain maturity has been shown to correspond to that of a slightly preterm neonate $[32,33]$, justifying the choice of the P6 rat pup as model animal. We found that baseline levels of the endogenous Hb-scavenger systems, Hp and Hpx, were low at P6 in the rat pup, which corresponds to the very low circulating levels observed in the newborn human infant $[18,19]$.

Intraperitoneal administration of cell-free $\mathrm{Hb}$ could be performed safely without local short- or long-term negative effects related to i.p. deposition. A reproducible and predictable uptake of cell-free human $\mathrm{Hb}$ into the systemic circulation was achieved, and the resulting systemic levels of cell-free $\mathrm{Hb}$ were similar to those reported in children on $\mathrm{CPB}$ [34]. Attempts to further increase the plasma levels by increased i.p. deposition were not successful due to limitations in volume and viscosity of the i.p. injectate and possibly also due to renal excretion of cell-free $\mathrm{Hb}$.

An important advantage of administering human cell-free $\mathrm{Hb}$ was that it enabled us to discriminate circulatory uptake of cell-free $\mathrm{Hb}$ from sampling-derived hemolysis. A possible disadvantage of this setting would be the risk of introduction of a protein foreign to the species, which in itself might provoke inflammatory and immunological reactions. However, as the three-dimensional structure of $\mathrm{Hb}$ in vertebrates is highly conserved throughout evolution [35], we do not think that the cross-species injection introduces a significant source of error in the interpretation of the results.

In our study, we found an increase in free heme at $3 \mathrm{~h}$ concurrent with the maximum levels of plasma cell-free $\mathrm{Hb}$. The difference in heme levels in relation to different oxygen environments at $3 \mathrm{~h}$ is interesting and indicates an accelerated $\mathrm{Hb}$ metabolism in a hyperoxic environment. The early rise in HMOX1 transcription is in accordance with this speculation. We interpret the lack of difference in heme-levels at $6 \mathrm{~h}$ as a 


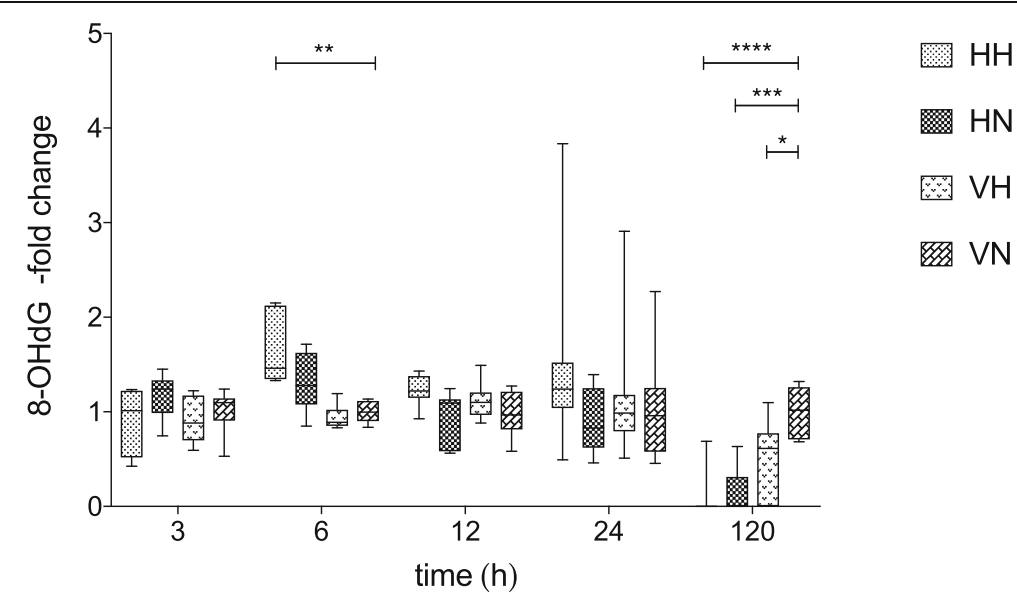

Fig. 6 DNA-oxidation in plasma. Systemic oxidative stress measured as DNA-oxidation (8-OHdG) in plasma at 3-120 h post i.p. injection. Fold change was calculated against VN-mean at each time point. $n=5-18$ in all groups. Results are presented as box-and-whisker plots with min and max values marked

consequence of the decreased absolute levels of cell-free $\mathrm{Hb}$ and, thus, a relative lack of substrate bringing free heme levels under the threshold of Hpx scavenging capacity.

Haptoglobin in plasma increased to a maximum 30-fold rise at $12 \mathrm{~h}$ in $\mathrm{Hb}$-injected animals compared to animals injected with vehicle. This finding is unexpected since exposure to cell-free $\mathrm{Hb}$ is commonly associated with a decrease in $\mathrm{Hp}$-levels as the $\mathrm{Hb}$ Hp complex is cleared from plasma. We considered the possibility that the many-fold surge in plasma concentrations of $\mathrm{Hp}$ represents an acute phase response as $\mathrm{Hp}$ is a well-recognized acute phase reactant in rodents [36], and indeed, we observed an increased transcription of $\mathrm{Hp}$ in liver tissue in both $\mathrm{Hb}$-exposed groups at $12 \mathrm{~h}$ that parallels maximal plasma concentrations. We did not find an altered glycosylation pattern of $\mathrm{Hp}$ as an indication of neutrophil-derived Hp-release into systemic circulation [37].

Hemopexin levels in $\mathrm{Hb}$-injected animals were approximately halved within $6 \mathrm{~h}$ of $\mathrm{Hb}$ injection in comparison with vehicle-injected animals signifying endocytosis and scavenging of the heme-Hpx complex. At $24 \mathrm{~h} \mathrm{Hpx-levels} \mathrm{were} \mathrm{almost} \mathrm{comparable} \mathrm{to}$ those in animals injected with vehicle and to baseline animals. This result is in line with the observed rapid decrease in levels of free heme. Hpx transcription in liver was increased at 3,12 , and $24 \mathrm{~h}$ in animals injected with cell-free $\mathrm{Hb}$, presumably as an endogenous response to consumption.

In mRNA analyses of $\mathrm{Hp}$ and $\mathrm{Hpx}$, the translational response was mitigated in the $\mathrm{HH}$ group as compared to the $\mathrm{HN}$ group. The attenuating effect of hyperoxia on hepatic regulation of $\mathrm{Hp}$ and $\mathrm{Hpx}$ was an unexpected finding. There are numerous reports of transcriptional modifications in different organs in the presence of hyperoxia [38, 39], but to the best of our knowledge, none of them encompass hepatic transcription of hemoglobin-scavenging genes. As of now, we do not have any immediate explanation of this finding. Another interesting observation in our model was the increase in hepatic transcription of all measured $\mathrm{Hb}$ - and hemescavenging proteins in response to hyperoxemia only $(\mathrm{VH})$ at $24 \mathrm{~h}$. The increased transcription indicates broader scavenging properties than previously thought.

The evidence of systemic toxicity and oxidative stress was supported by the pattern of plasma DNA-oxidation found both with singular and combined insults. We believe 
that the increase in DNA-oxidation at $6 \mathrm{~h}$ supports the idea that combined exposure to cell-free $\mathrm{Hb}$ and hyperoxia results in additive oxidative stress in an immature physiology. The significant decrease in DNA-oxidation at $120 \mathrm{~h}$ in all groups exposed to any insult $(\mathrm{HH}, \mathrm{HN}$, and $\mathrm{VH})$ may be interpreted as an activation of DNA repair mechanisms as a result of induced oxidative stress. Whether this oxidative stress translates into clinically significant end organ damage remains to be investigated.

A possible limitation of using rats for evaluation of cell-free $\mathrm{Hb}$ toxicity is the rat's ability to produce ascorbic acid, a significant antioxidant as shown in adult rats [40, 41]. Humans rely on dietary supplement of ascorbic acid as do guinea pigs, the only rodent with a similar incapability of endogenous production. However, as we aimed to mimic a neonatal physiology, guinea pigs were not a preferred alternative due to their accelerated brain maturity at birth [42]. We analyzed plasma levels of ascorbic acid and mRNA expression of the GULO-enzyme in liver tissue (data not shown), but in neither analyses did we obtain reproducible results. We acknowledge the fact that our immature rat model probably has an increased inherent capacity of antioxidant defenses compared to humans, and may only speculate upon possible consequences.

\title{
Conclusions
}

In this manuscript, we present data of a novel rat pup model mimicking two potentially injurious aspects of CPB in newborn infants. We have shown that i.p. injection of cellfree $\mathrm{Hb}$ is a feasible way of achieving a predictable and reproducible level of systemic cell-free $\mathrm{Hb}$ with a consistent plasma scavenger response. We have established baseline Hb-scavenging properties similar to those of the human newborn. We have indications of an accelerated metabolism of plasma cell-free $\mathrm{Hb}$ and of an altered transcriptional regulation of scavenging proteins in a hyperoxic environment. Our results suggest an activation of DNA repair mechanisms following all insults, singular or combined. We believe that the presented animal model is valuable and well suited for further investigations on organ-specific consequences of systemic hemolysis and concomitant hyperoxemia in an immature physiology.

\section{Additional file}

Additional file 1: Dataset supporting our results. (XLSX $81 \mathrm{~kb})$

\author{
Abbreviations \\ CHD: Congenital heart defect; CPB: Cardiopulmonary bypass; Hb: Hemoglobin; HMOX-1: Heme oxygenase 1; \\ Hp: Haptoglobin; Hpx: Hemopexin; i.p.: Intraperitoneal; P: Postnatal day \\ Funding \\ This work was funded by the Swedish Research Council, grant nr 2014-3140, the Swedish Heart-Lung Foundation grant \\ nrs 20140631 and 20160721, ALF government grants to Lund University, the Skåne Council Foundation for Research \\ and Development, the European Commission FP7 project 305485 PREVENT-ROP, Queen Silvias foundation, Lilla barnets \\ fond, the Crafoord Foundation, the Greta and Johan Kock Foundation, the Alfred Österlund Foundation, and Fanny \\ Ekdahls foundation.
}

Availability of data and materials

The dataset supporting the conclusions of this article are included within the article and its Additional file 1. 
revision of the manuscript. MG contributed to conception and design of the study; acquisition, analysis, and interpretation of data; and revision of the manuscript. DL contributed to conception and design of the study; acquisition and interpretation of data; and revision of the manuscript. All authors have given final approval of the manuscript to be published.

\section{Ethics approval}

The research protocol was approved by the Swedish Animal Ethics Committee in Lund, permit nr M48-14.

\section{Consent for publication}

Not applicable.

\section{Competing interests}

The author MG is co-founder and shareholder of the company A1M Pharma AB. The other authors declare that they have no competing interests.

\section{Publisher's Note}

Springer Nature remains neutral with regard to jurisdictional claims in published maps and institutional affiliations.

\section{Author details}

'Department of Clinical Sciences Lund, Pediatrics, Skane University Hospital, Lund University, Lund, Sweden.

${ }^{2}$ Department of Clinical Sciences Lund, Pediatric Surgery and Neonatal Care, Skane University Hospital, Lund University, Lund, Sweden. ${ }^{3}$ Department of Clinical Sciences Lund, Infection Medicine, Lund University, Lund, Sweden. ${ }^{4}$ Pediatric Intensive Care Unit (BIVA), Skane University Hospital, Lund, Sweden.

\section{Received: 27 March 2017 Accepted: 21 August 2017}

Published online: 04 October 2017

\section{References}

1. Volpe JJ (2014) Encephalopathy of congenital heart disease-destructive and developmental effects intertwined. J Pediatr 164(5):962-965

2. Marino BS, Lipkin PH, Newburger JW et al (2012) Neurodevelopmental outcomes in children with congenital heart disease: evaluation and management: a scientific statement from the American Heart Association. Circulation 126(9):1143-1172

3. Kozik DJ, Tweddell JS (2006) Characterizing the inflammatory response to cardiopulmonary bypass in children. Ann Thorac Surg 81(6):S2347-S2354

4. Christen S, Finckh B, Lykkesfeldt J et al (2005) Oxidative stress precedes peak systemic inflammatory response in pediatric patients undergoing cardiopulmonary bypass operation. Free Radic Biol Med 38(10):1323-1332

5. Fudulu D, Angelini G (2016) Oxidative stress after surgery on the immature heart. Oxidative Med Cell Longev 2016: Article ID 1971452

6. Warren OJ, Smith AJ, Alexiou C et al (2009) The inflammatory response to cardiopulmonary bypass: part 1-mechanisms of pathogenesis. J Cardiothorac Vasc Anesth 23(2):223-231

7. Windsant ICV, Hanssen SJ, Buurman WA, Jacobs MJ (2011) Cardiovascular surgery and organ damage: time to reconsider the role of hemolysis. J Thorac Cardiovasc Surg 142(1):1-11

8. Mamikonian LS, Mamo LB, Smith PB, Koo J, Lodge AJ, Turi JL (2014) Cardiopulmonary bypass is associated with hemolysis and acute kidney injury in neonates, infants, and children*. Pediatr Crit Care Med 15(3):e111-e119

9. Rezoagli E, Ichinose F, Strelow S et al (2016) Pulmonary and systemic vascular resistances after cardiopulmonary bypass: role of hemolysis. YJCAN 31(2):505-515

10. Gladwin MT, Kanias T, Kim-Shapiro DB (2012) Hemolysis and cell-free hemoglobin drive an intrinsic mechanism for human disease. J Clin Invest 122(4):1205-1208

11. Olsson MG, Allhorn M, Bülow L et al (2012) Pathological conditions involving extracellular hemoglobin: molecular mechanisms, clinical significance, and novel therapeutic opportunities for a 1-microglobulin. Antioxid Redox Signal 17(5):813-846

12. Kumar S, Bandyopadhyay U (2005) Free heme toxicity and its detoxification systems in human. Toxicol Lett 157(3): $175-188$

13. Wagener FADTG, Eggert A, Boerman OC et al (2001) Heme is a potent inducer of inflammation in mice and is counteracted by heme oxygenase. Blood 98:1802-1811

14. Lorne E, Dupont H, Abraham E (2010) Toll-like receptors 2 and 4: initiators of non-septic inflammation in critical care medicine? Intensive Care Med 36(11):1826-1835

15. Schaer DJ, Alayash Al (2010) Clearance and control mechanisms of hemoglobin from cradle to grave. Antioxid Redox Signal 12(2):181-184

16. Smith A, McCulloh RJ (2015) Hemopexin and haptoglobin: allies against heme toxicity from hemoglobin not contenders. Front Physiol 6:187. doi:10.3389/fphys.2015.00187. eCollection 2015

17. Nielsen MJ, Møller HJ, Moestrup SK (2010) Hemoglobin and Heme scavenger receptors. Antioxid Redox Signal 12(2):261-273

18. Chavez-Bueno S, Beasley JA, Goldbeck JM et al (2011) Haptoglobin concentrations in preterm and term newborns. J Perinatol 31(7):500-503

19. Kanakoudi F, Droussou V, Tzimouli $V$ et al (1995) Serum concentrations of 10 acute-phase proteins in healthy term and preterm infants from birth to age 6 months. Clin Chem 41:605-608

20. Gerstner B, DeSilva TM, Genz K et al (2008) Hyperoxia causes maturation-dependent cell death in the developing white matter. J Neurosci 28(5):1236-1245 
21. Markus T, Hansson S, Amer-Wåhlin I, Hellström-Westas L, Saugstad OD, Ley D (2007) Cerebral inflammatory response after fetal asphyxia and hyperoxic resuscitation in newborn sheep. Pediatr Res 62(1):71-77

22. Kagawa H, Morita K, Uno Y et al (2014) Inflammatory response to hyperoxemic and normoxemic cardiopulmonary bypass in acyanotic pediatric patients. World J Pediatr Congenit Heart Surg 5(4):541-545

23. Caputo M, Mokhtari A, Rogers CA et al (2009) The effects of normoxic versus hyperoxic cardiopulmonary bypass on oxidative stress and inflammatory response in cyanotic pediatric patients undergoing open cardiac surgery: a randomized controlled trial. J Thorac Cardiovasc Surg 138(1):206-214

24. Sheil ML, Luxford C, Davies MJ, Peat JK, Nunn G, Celermajer DS (2005) Protein oxidation injury occurs during pediatric cardiopulmonary bypass. J Thorac Cardiovasc Surg 130(4):1054-1061

25. Winterbourn CC (1990) Oxidative reactions of hemoglobin. Methods Enzymol 186:265-272

26. Rather $\amalg(1948)$ Renal athrocytosis and intracellular digestion of intraperitoneally injected hemoglobin in rats. J Exp Med 87(2):163-174

27. Saugstad OD, Sejersted Y, Solberg R, Wollen EJ, Bjørås M (2012) Oxygenation of the newborn: a molecular approach. Neonatology 101(4):315-325

28. Brehmer F, Bendix I, Prager S et al (2012) Interaction of inflammation and hyperoxia in a rat model of neonatal white matter damage. PLoS One 7(11):e49023

29. Gill R, Tsung A, Billiar T (2010) Linking oxidative stress to inflammation: toll-like receptors. Free Rad Biol Med 48(9): $1121-1132$

30. Morgan MJ, Liu Z-G (2010) Crosstalk of reactive oxygen species and NF-Kb signaling. Nat Publ Group 21(1):103-115

31. Semple BD, Blomgren K, Gimlin K, Ferriero DM, Noble-Haeusslein LJ (2013) Brain development in rodents and humans: identifying benchmarks of maturation and vulnerability to injury across species. Prog Neurobiol 106-107: $1-16$

32. Miller SP, McQuillen PS, Hamrick S et al (2007) Abnormal brain development in newborns with congenital heart disease. N Engl J Med 357(19):1928-1938

33. McQuillen PS, Miller SP (2010) Congenital heart disease and brain development. Ann N Y Acad Sci (1184):68-86

34. Ricci Z, Pezzella C, Romagnoli S et al (2014) High levels of free haemoglobin in neonates and infants undergoing surgery on cardiopulmonary bypass. Interact Cardiovasc Thorac Surg 19(2):183-187

35. Sousounis K, Haney CE, Cao J, Sunchu B, Tsonis PA (2012) Conservation of the three-dimensional structure in nonhonologous or unrelated proteins. Hum Genomics 6:1-10

36. Cray C, Zaias J, Altman NH (2009) Acute phase response in animals: a review. Comp Med 59(6):517-526

37. Theilgaard-Monch K (2006) Haptoglobin is synthesized during granulocyte differentiation, stored in specific granules, and released by neutrophils in response to activation. Blood 108(1):353-361

38. Bhattacharya S, Zhou Z, Yee M et al (2014) The genome-wide transcriptional response to neonatal hyperoxia identifies Ahr as a key regulator. Am J Physiol Lung Cell Mol Physiol 307(7):L516-L523

39. Wollen EJ, Sejersted Y, Wright MS et al (2013) Transcriptome profiling of the newborn mouse brain after hypoxiareoxygenation: hyperoxic reoxygenation induces inflammatory and energy failure responsive genes. Pediatr Res 75(4):517-526

40. Buehler PW, D'Agnillo F, Hoffman V, Alayash Al (2007) Effects of endogenous ascorbate on oxidation, oxygenation, and toxicokinetics of cell-free modified hemoglobin after exchange transfusion in rat and guinea pig. J Pharmacol Exp Ther 323(1):49-60

41. Butt OI, Buehler PW, D'Agnillo F (2010) Differential induction of renal heme oxygenase and ferritin in ascorbate and nonascorbate producing species transfused with modified cell-free hemoglobin. Antioxid Redox Signal 12(2):199-208

42. Clancy B, Finlay BL, Darlington RB, Anand KJS (2007) Extrapolating brain development from experimental species to humans. Neurotoxicology 28(5):931-937

\section{Submit your manuscript to a SpringerOpen ${ }^{\circ}$ journal and benefit from:}

- Convenient online submission

- Rigorous peer review

- Open access: articles freely available online

- High visibility within the field

- Retaining the copyright to your article

Submit your next manuscript at $\gg$ springeropen.com 